\title{
Oral isoflavone supplementation on endometrial thickness: a meta-analysis of randomized placebo-controlled trials
}

\author{
Jie Liư ${ }^{1}$, Feixiang Yuan', Jian Gao², Boer Shan ${ }^{3}$, Yulan Ren ${ }^{3}$, Huaying Wang ${ }^{3}$ and \\ Ying Gao ${ }^{1}$ \\ ${ }^{1}$ Key Laboratory of Nutrition and Metabolism, Institute for Nutritional Sciences, Shanghai Institutes for Biological Sciences, \\ Chinese Academy of Sciences, Shanghai, China \\ ${ }^{2}$ Nutrition Department, Affiliated Zhongshan Hospital of Fudan University, Shanghai, China \\ ${ }^{3}$ Department of Female Tumor, Fudan University Shanghai Cancer Center, Shanghai, China \\ Correspondence to: Ying Gao, email: yinggao@sibs.ac.cn \\ Keywords: isoflavone supplementation, endometrial thickness, meta-analysis, randomized controlled trials, Gerotarget \\ Received: January 25, $2016 \quad$ Accepted: February 23, $2016 \quad$ Published: March 07, 2016
}

\section{ABSTRACT}

Background: Isoflavone from soy and other plants modulate hormonal effects in women, and the hormone disorder might result in different caners including endometrial cancer. However, it's effect on the risk of endometrial cancer is still inconclusive. We aimed to assess the effects of isoflavone on endometrial thickness, a risk factor of endometrial cancer in peri- and post-menopausal women.

Methods: A meta-analysis of randomized controlled trials was conducted to evaluate the effect of oral isoflavone supplementation on endometrial thickness in peri- and post-menopausal women. Electronic searches were performed on the PubMed, Embase, the Cochrane Library, web of science, CINAHL, and WHO ICTRP to August $1^{\text {st }}, 2015$. Reviews and reference lists of relevant articles were also searched to identify more studies. Summary estimates of standard mean differences (SMD's) and $\mathbf{9 5 \%}$ CIs were obtained with random-effects models. Heterogeneity was evaluated with meta-regression and stratified analyses.

Results: A total of $\mathbf{2 3}$ trials were included in the current analysis. The overall results did not show significant change of endometrial thickness after oral isoflavone supplementation ( 23 studies, 2167 subjects; SMD:-0.05; 95\%CI:-0.23, $0.13 ; P=0.60$ ). Stratified analysis suggested that a daily dose of more than $54 \mathrm{mg}$ could decrease the endometrial thickness for $0.26 \mathrm{~mm}$ ( 10 trials, 984subjects; SMD:-0.26; 95\%CI:-0.45, $-0.07 ; P=0.007$ ). Furthermore, isoflavone supplementation significantly decrease the endometrial thickness for $0.23 \mathrm{~mm}$ in North American studies ( 7 trials, 726 subjects; SMD:-0.23; 95\%CI:-0.44, -0.01; $P=0.04)$, but it suggested an increase for $0.23 \mathrm{~mm}$ in Asian studies ( 3 trials, 224 subjects; SMD: 0.23; 95\%CI:-0.04, 0.50; $P=0.10$ ).

Conclusion: Oral isoflavone supplementation might have different effects in different populations and at different daily doses. Multiple-centre, larger, and longterm trials are deserved to further evaluate its effect.

\section{INTRODUCTION}

In the endometrium, excess estrogen relative to progesterone produces a proliferative stimulus, which may result in endometrial thickening. As measured by transvaginal ultrasound (TVU), endometrial thickness can be a biomarker for the proliferative effects of estrogens, and opposing different influences of progesterone. The increase of endometrial thickness may be associated with increased risk of endometrial carcinomas [1,2].

Phytoestrogens are plant-derived chemicals [3]. There is a large family of different classes of phytoestrogens, and isoflavones are the major type with highest activity that have been given therapeutically to women [4]. The structure of plant-derived isoflavone is similar to human $17 \beta$-estradiol. Isoflavones show selective estrogen receptor modulator like activity, though it's estrogenic and anti-estrogenic effects vary depending on 
the receptors of different target tissues [5]. This stimulated significant interest in the importance of isoflavone to women's health [6].

Isoflavone, mainly produced by soybeans, has been suggested to have estrogenic effects in human studies. Epidemiology studies suggested that dietary isoflavone could influence hormonal levels in women [7]. There have been many studies shown that given isoflavone product to postmenopausal women might relieve menopausal symptoms such as hot flushes and vaginal dryness [8, 9]. There are also studies evaluated the effect of oral isoflavone supplementation on endometrial thickness, a risk factor of endometrial cancer [10-32]. However, the results were not consistent, and the sample sizes were relatively small (vary from 15 to 401). Therefore, we searched all published, double-blinded, randomized and controlled trials, and conducted a meta-analysis to systematically evaluate the effect of isoflavone supplementation on endometrial thickness.

\section{RESULTS}

\section{Search results}

The procedure of selection of studies is shown in Figure 1. In total, 2542 articles were identified in a combined search of the PubMed, Embase, Cochrane Library and web of science, CINAHL and WHO ICTRP databases, and reference lists of relevant articles (relevant text words "isoflavone" paired with "endometrial" or "endometrium" are used for searching). Of the 2542 articles, 2506 were excluded because they were animal experiments, in vivo experiments, or not relevant through abstract. After further excluded studies in which isoflavone intervention method was not appropriate, endometrial thickness measurements were not performed, endometrial thickness values were not reported, or the studies were not randomized placebo-controlled studies, 23 eligible randomized controlled studies [10-32] were finally left in the current meta-analysis.

\section{-1076 articles found in CINAHL search \\ -563 articles found in WHO ICRTP search \\ -74 articles found in Cochrane search \\ -952 articles found in Embase search \\ -681 articles found in Pubmed search \\ -793 articles found in web of science search}

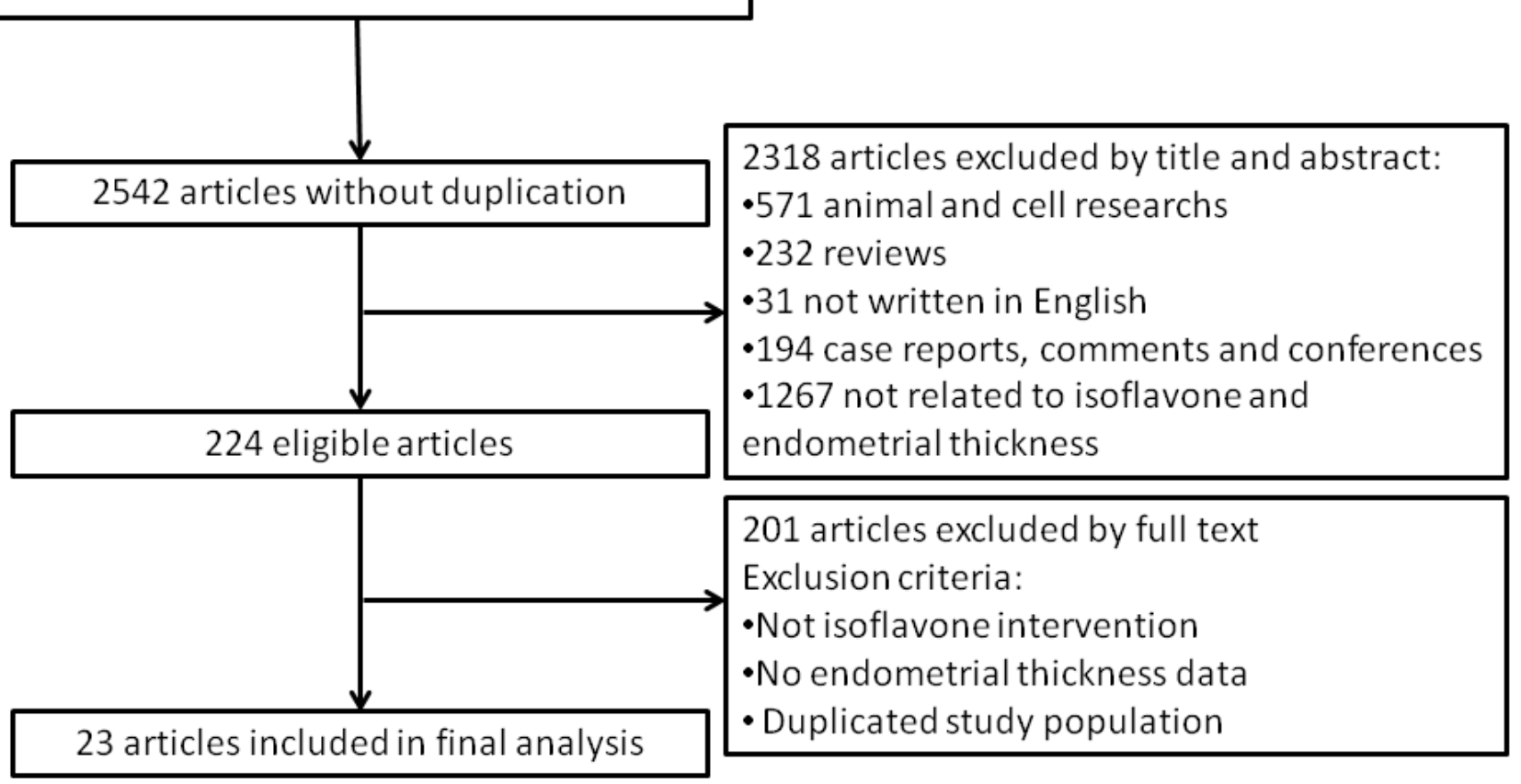

Figure 1: Identification process for eligible studies 


\section{Description of the included studies}

All of the included studies are randomized controlled trials (RCT). For a study with a crossover design, data from the first stage were extracted for the current study [25]. Total 2305 subjects from the 23 RCTs were included in the current analysis. The intervention duration lasted from 3 months to 3 years. The average age of the subjects ranged from 47 to 73 years. The details of characteristics of these studies are shown in Table 1.

Except two of the studies included peri-menopausal women [30,31], all others only included post-menopausal women. Three studies provided red clover-based isoflavone supplements $[18,24,31]$, one provided pueraria mirifica-based isoflavone supplements [19], seven provided additional soy foods $[10,13,16,21$, $23,28,32]$, one provided soy protein powder [12], two provided synthetic isoflavone $[14,15]$, and the other nine provided soy-based isoflavone supplements $[11,17,20$, $22,25-27,29-30]$. All the studies reported no side effect of supplementation in articles. Isoflavone supplementation doses ranged from 5 to $154 \mathrm{mg} / \mathrm{d}$ and supplementation duration ranged from 12 to 156 weeks. Control groups received placebo and were advised to keep their usual diet. All studies evaluated endometrial thickness by transvaginal ultrasounds. The baseline endometrial thickness varied from $0.4 \pm 2.3 \mathrm{~mm}$ to $7.25 \pm 2.88 \mathrm{~mm}$.

\section{Data quality}

The quality of the 23 studies ranged from 3 to 5 scores (highest score). Exact details of randomization ( mention of randomization methods, appropriateness of randomization), blinding (mention of blinding methods, appropriateness of blinding), and dropout (the fate of all patients in the trial was known) were reported in 14 studies [10, 12-15, 17, 20-23, 26, 28, 30-31], but not all mentioned in the other 9 studies [11, 16, 18-19, 24-25, 27, $29,32]$.

\section{Effects of oral supplementation of isoflavone on endometrial thickness}

The primary outcome of current study was the changes of the endometrial thickness compared to baseline after isoflavone supplementation. Three studies $[12,16,18]$ reported the absolute changes of endometrial thickness, and the remaining 20 studies provided baseline and final endometrial thickness after intervention.

The overall results from pooling the 23 studies did not show significant change in endometrial thickness in either treatment or placebo groups (23 studies, 2167 subjects; SMD:-0.05; 95\%CI:-0.23, 0.13; $P=0.60$ ) (Figure 2). Significant heterogeneity for the outcome was found $\left(\mathrm{Chi}^{2}=87.23, \mathrm{I}^{2}=74 \%, P<0.00001\right)$. To detect the source of the heterogeneity, meta-regression and stratified analysis were performed. Meta-regression analysis

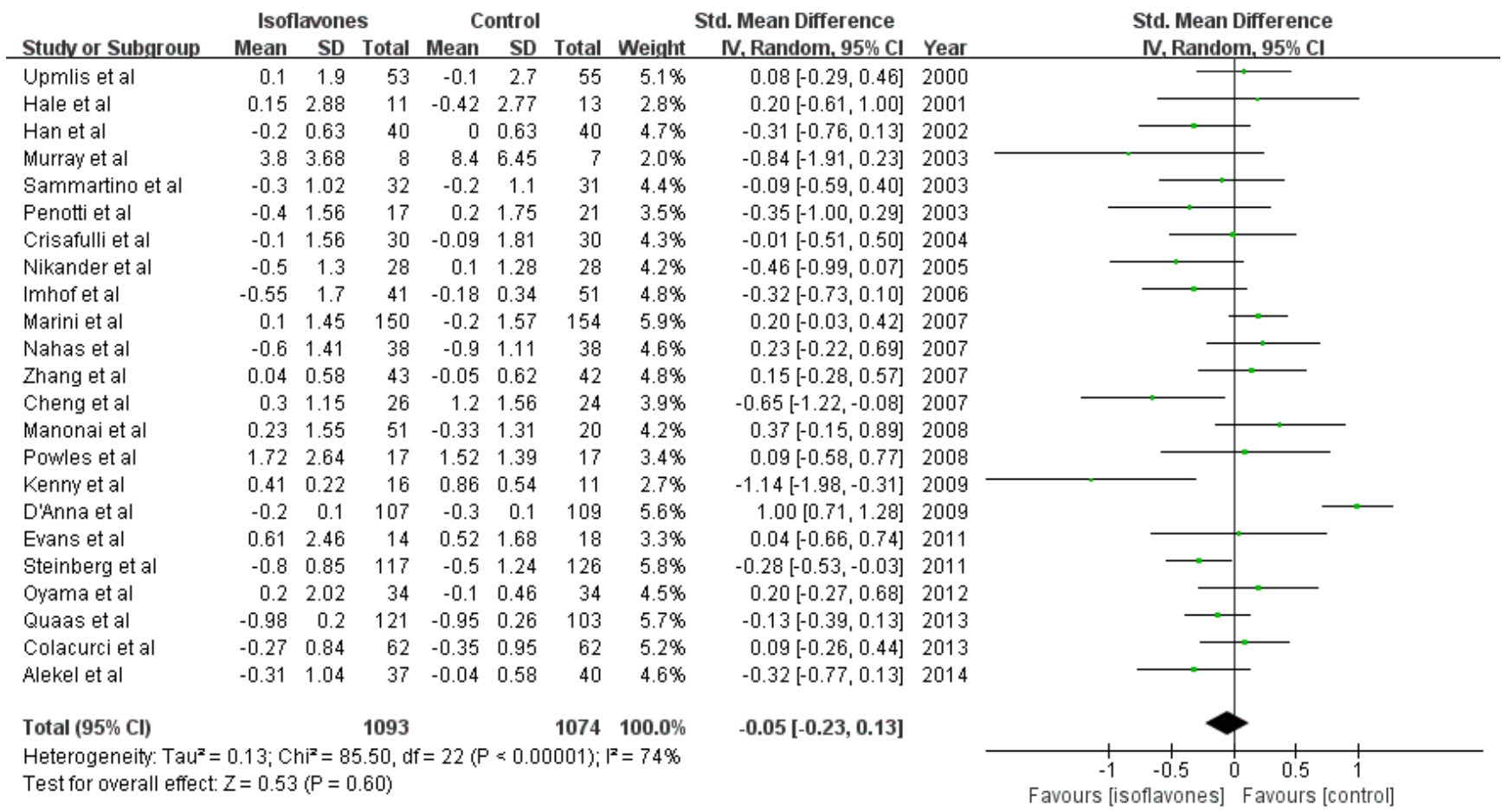

Figure 2: Meta-analysis of the effect of isoflavone supplementation on endometrial thickness. The sizes of the data markers indicate the weight of each study in the analysis. 
Table1: Characteristics of studies

\begin{tabular}{|c|c|c|c|c|c|c|c|c|c|c|}
\hline Reference & Year & Study design & Participants & $\begin{array}{l}\text { No. of } \\
\text { subjec } \\
\text { ts }\end{array}$ & $\begin{array}{l}\text { Geographic } \\
\text { regions }\end{array}$ & $\begin{array}{l}\text { Baseline } \\
\text { endometrial } \\
\text { thickness }{ }^{1} \mathbf{T}^{2} \\
(\mathrm{~mm})\end{array}$ & $\begin{array}{l}\text { Baseline } \\
\text { endometrial } \\
\text { thickness }{ }^{1}{ }_{-} C^{2} \\
(\mathrm{~mm})\end{array}$ & $\begin{array}{l}\text { Isoflavone } \\
\text { dose } \\
(\mathrm{mg} / \mathrm{d})\end{array}$ & Source of isoflavone & $\begin{array}{l}\text { Study } \\
\text { duration } \\
\text { (week) }\end{array}$ \\
\hline D.H.Upmlis et al. & 2000 & Double-blind RCT & postmenopausal & 122 & USA & $3.5 \pm 1.9$ & $3.7 \pm 2.7$ & 50 & Soy & 12 \\
\hline G. E. Hale et al. & 2001 & Double-blind RCT & Perimenopausal & 24 & Austria & $7.09 \pm 2.85$ & $6.46 \pm 1.7$ & 50 & Red clover & 12 \\
\hline Kyung K.Han et al. & 2002 & Double-blind RCT & Perimenopausal & 80 & Brazil & $3.3 \pm 0.1 \mathrm{SE}$ & $2.6 \pm 0.1 \mathrm{SE}$ & 100 & Isoflavone tablet & 16 \\
\hline A.Sammartino et al. & 2003 & RCT & postmenopausal & 63 & Europe & $3.2(2.3-4.5)$ & $3.1(2.3-4.2)$ & 36 & Genistein & 48 \\
\hline M.J.Murray et al. & 2003 & RCT & postmenopausal & 15 & USA & $3 \pm 1$ & $3.6 \pm 1.6$ & 120 & Isoflavone tablet & 24 \\
\hline M.Penotti et al. & 2003 & Double-blind RCT & postmenopausal & 62 & Europe & $2.6 \pm 1.8$ & $3.2 \pm 1.8$ & 36 & Soy & 24 \\
\hline A.Crisafulli et al. & 2004 & Double-blind RCT & postmenopausal & 60 & Europe & $3.2 \pm 0.25 \mathrm{SE}$ & $3.3 \pm 0.33 \mathrm{SE}$ & 54 & Isoflavone tablet & 48 \\
\hline E.Nikander et al. & 2005 & $\begin{array}{l}\text { double blind cross over } \\
\text { RCT }\end{array}$ & postmenopausal & 56 & Europe & $2.4 \pm 1.5$ & $2.1 \pm 1.1$ & 114 & Isoflavone tablet & 12 \\
\hline M.Imhof et al. & 2006 & crossover RCT & postmenopausal & 109 & Austria & 1 & / & 80 & Red clover & 13 \\
\hline E.A.P.Nahas et al. & 2007 & Double-blind RCT & postmenopausal & 76 & Brazil & $\begin{array}{l}\text { 3median }(2.2-4.1) \\
25-75 \text { th }\end{array}$ & $\begin{array}{l}\text { 3.7median }(2.6-4.1 \\
\text { 25-75th }\end{array}$ & 100 & Glycine max & 40 \\
\hline G.Cheng et al. & 2007 & $\begin{array}{l}\text { Double-blind prospective } \\
\text { randomized study }\end{array}$ & postmenopausal & 51 & Europe & $2.3 \pm 1.1$ & $2 \pm 1$ & 60 & Soya beans & 12 \\
\hline H.Marini et al. & 2007 & Double-blind RCT & postmenopausal & 389 & Italy & $3.1 \pm 1.5$ & $3.2 \pm 1.8$ & 54 & Isoflavone tablet & 104 \\
\hline G.Zhang et al. & 2007 & Double-blind RCT & postmenopausal & 100 & China & $1.82 \pm 0.62$ & $1.75 \pm 0.58$ & 18 & Isoflavone tablet & 12 \\
\hline J.Manonai et al. & 2008 & Double-blind RCT & postmenopausal & 71 & Asia & $4.07 \pm 1.48$ & $4.07 \pm 1.39$ & $20,30,50$ & Pueraria mirifica & 24 \\
\hline T.J.Powles et al. & 2008 & Double-blind RCT & postmenopausal & 401 & England & 1 & 1 & 40 & Red clover & 156 \\
\hline A.M.Kenny et al. & 2009 & Double-blind RCT & postmenopausal & 66 & USA & $2.97 \pm 0.81$ & $3.14 \pm 0.81$ & 57 & Soy & 52 \\
\hline R.D’Anna et al. & 2009 & RCT & postmenopausal & 397 & Europe & $3.1 \pm 0.1 \mathrm{SE}$ & $3.2 \pm 0.1 \mathrm{SE}$ & 54 & Isoflavone tablet & 104 \\
\hline F.M.Steinberg et al. & 2011 & Double-blind RCT & postmenopausal & 268 & Multicenter & $1.8 \pm 0.98$ & $2 \pm 1.22$ & 102.3 & Synthetic & 104 \\
\hline M.Evans et al. & 2011 & Double-blind RCT & postmenopausal & 83 & Canada & $4.28 \pm 1.98$ & $3.66 \pm 1.21$ & 30 & Synthetic & 12 \\
\hline A.Oyama et al. & 2012 & Double-blind RCT & postmenopausal & 68 & Japan & $0.2 \pm 0.8$ & $0.1 \pm 0.5$ & 5 & Soy germ fermentation & 12 \\
\hline A.M.Quaas et al. & 2013 & Double-blind RCT & postmenopausal & 224 & USA & $2.4 \pm 1$ & $2.5 \pm 1.1$ & 154 & Isolated soy protein & 156 \\
\hline N.Colacurci et al. & 2013 & $\mathrm{RCT}$ & postmenopausal & 124 & Europe & $3.35 \pm 0.95$ & $3.47 \pm 1.07$ & 60 & Isoflavone tablet & 48 \\
\hline D.L.Alekel et al. & 2014 & Double-blind RCT & postmenopausal & 168 & USA & $1.7 \pm 1.1$ & $1.3 \pm 0.65$ & 120 & Soy bean & 156 \\
\hline
\end{tabular}

${ }^{1}$ All values are the means \pm SDs, means \pm SEs, mean (range), median $\left(25^{\text {th }}-75^{\text {th }}\right.$ range $)$, or mean $(95 \% \mathrm{CI})$ reported in the trial

${ }^{2} \mathrm{~T}$ : treatment group, C: control group

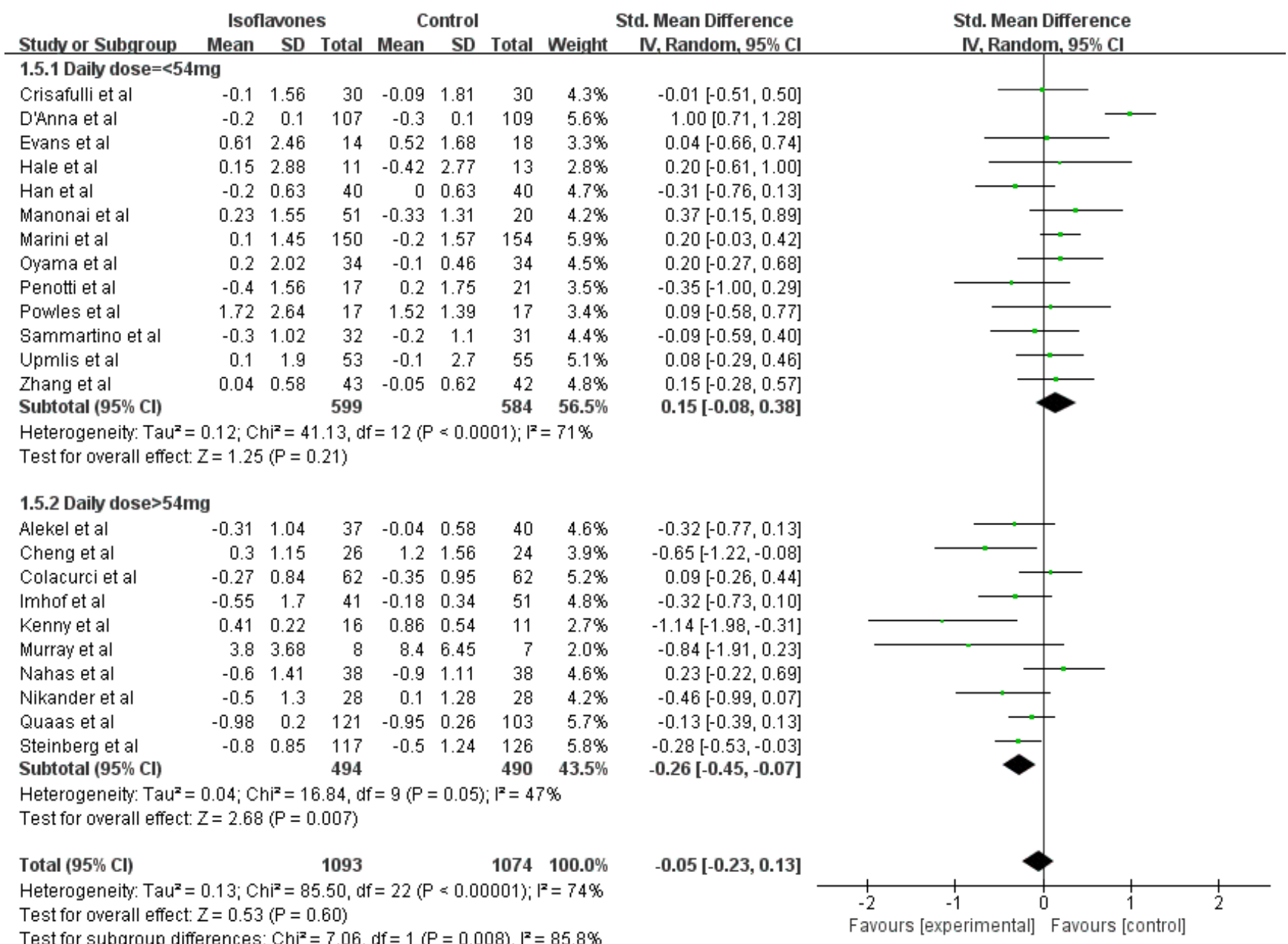

Figure 3: Meta-analysis of subgroup by geographic regions of study objects. The sizes of the data markers indicate the weight of each study in the analysis. The geographic region is differentiated by study geographic region reported by trials. 
showed that geographic region of the subjects (regression coefficient $=-1.17 ; 95 \% \mathrm{CI}:-1.97,-0.37 P=0.004)$ and daily dose of isoflavone supplementation were negatively related to the effect size of heterogeneity (regression coefficient $=-0.008 ; 95 \% \mathrm{CI}:-0.19,-0.02 P=0.05)$. The source of isoflavone (results not shown) and total dose of isoflavone supplementation did not modify the effect substantially according to meta-regression.

To explore the modification effect, we performed stratified analysis according to median age, BMI, menopausal state, geographic regions, isoflavone total dose, and isoflavone daily dose (Table 2). We found that a significant decrease of endometrial thickness $(-0.23 \mathrm{~mm})$ after isoflavone supplementation intervention (7 trials, 726 subjects; SMD:-0.23; 95\%CI:-0.44, $-0.01 ; P=0.04)$ in subjects from North America. This was opposite to an increased change $(0.23 \mathrm{~mm})$ observed in Asian subjects (3 trials, 224 subjects; SMD: 0.23; 95\%CI:-0.04, 0.50; $P=$ 0.10 ) (Figure 2). When daily isoflavone supplementation dose was more than $54 \mathrm{mg}$ the endometrial thickness was decreased $(-0.26 \mathrm{~mm})$ significantly (10 trials, 984subjects; SMD:-0.26; 95\%CI:-0.45, $-0.07 ; P=0.007)$ but the change was not significant $(0.15 \mathrm{~mm})$ when the dose was less than 54mg (13 trials, 1183 subjects; SMD: 0.15; 95\%CI:-0.08, $0.38 ; P=0.21$ ) (Figure 3 ). The study subjects of daily dose more than $54 \mathrm{mg}$ were all post-menopausal women. No

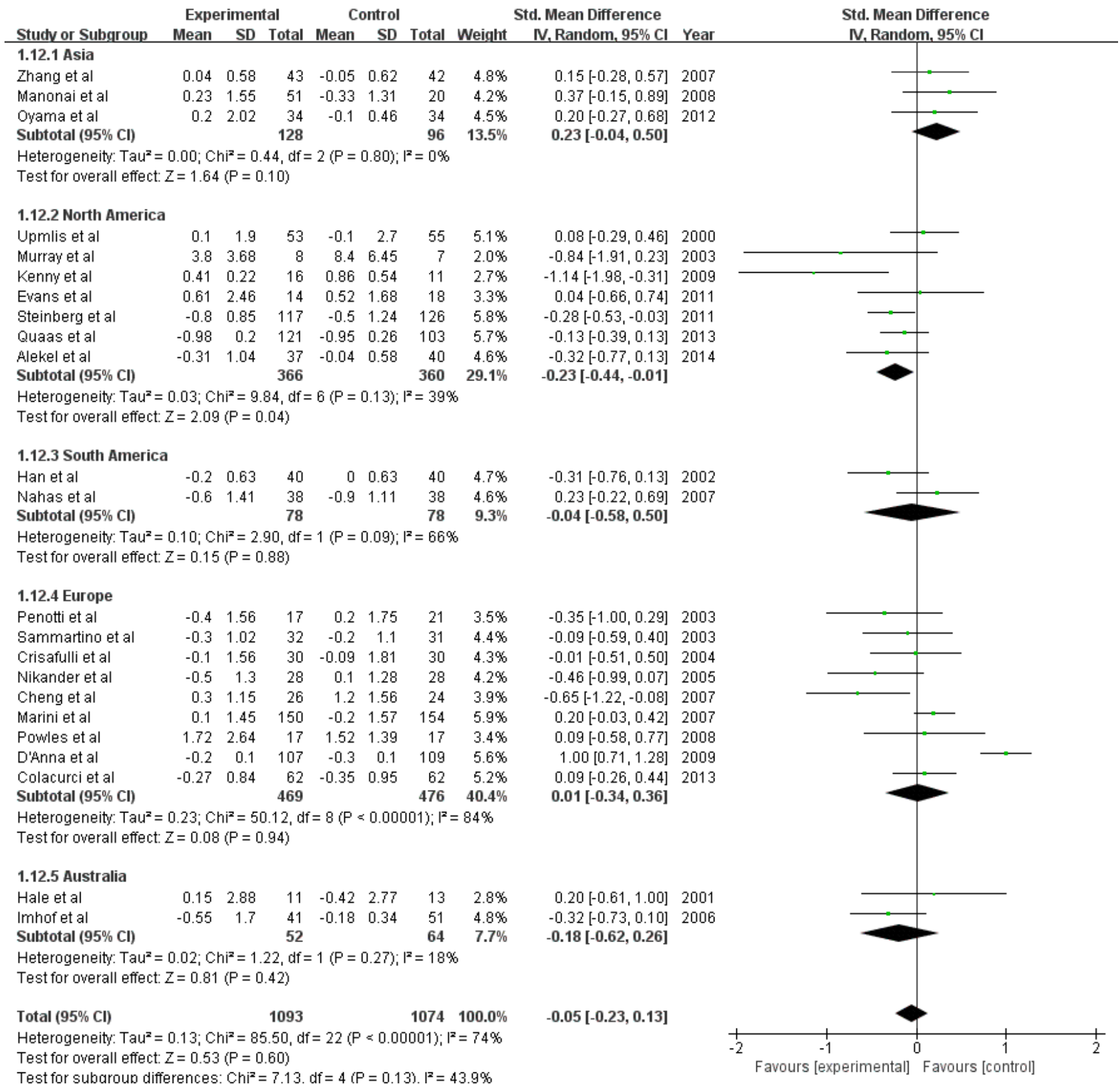

Figure 4: Meta-analysis of subgroup by dose of daily isoflavone supplementation. The sizes of the data markers indicate the weight of each study in the analysis. The daily dose is based on the data counted by trials. 
Table2: Subgroup analyses for the effect of oral isoflavone supplementation on endothelial thickness

\begin{tabular}{|c|c|c|c|c|}
\hline & Study number & Number of subjects & SMD $^{1}(95 \% C I)$ & $\mathbf{P}^{2}$ \\
\hline Age & & & & 0.84 \\
\hline$\leq 60 \mathrm{y}$ & 20 & 1931 & $-0.02(-0.22,0.18)$ & \\
\hline$>60 y$ & 3 & 336 & $-0.24(-0.75,0.26)$ & \\
\hline Daily Isoflavone dose & & & & 0.007 \\
\hline$\leq 54 \mathrm{mg} / \mathrm{d}$ & 13 & 1183 & $0.15(-0.08,0.38)$ & \\
\hline$>54 \mathrm{mg} / \mathrm{d}$ & 10 & 984 & $-0.26(-0.45,-0.07)$ & \\
\hline Total isoflavone dose & & & & 0.30 \\
\hline$\leq 14000 \mathrm{mg}$ & 12 & 767 & $-0.09(-0.27,0.08)$ & \\
\hline$>14000 \mathrm{mg}$ & 11 & 1400 & $-0.02(-0.32,0.28)$ & \\
\hline BMI & & & & 0.07 \\
\hline$\leq 25 \mathrm{~kg} / \mathrm{m}^{2}$ & 11 & 1137 & $0.05(-0.24,0.35)$ & \\
\hline$>25 \mathrm{~kg} / \mathrm{m}^{2}$ & 9 & 760 & $-0.19(-0.40,0.01)$ & \\
\hline Geographic regions & & & & 0.04 \\
\hline North America & 7 & 726 & $-0.04(-0.58,0.50)$ & \\
\hline South America & 2 & 156 & $-0.23(-0.44,-0.01)$ & \\
\hline Asia & 3 & 224 & $0.23(-0.04,0.50)$ & \\
\hline Australia & 2 & 116 & $-0.18(-0.62,0.26)$ & \\
\hline Europe & 9 & 945 & $0.01(-0.34,0.36)$ & \\
\hline
\end{tabular}

SMD: standard mean difference

${ }^{2} \mathrm{P}$ value is from the meta-analysis of total effect of each subgroup, assessed by random-effect models

significant modification effect was observed for median age, BMI, menopausal state, and isoflavone total dose.

\section{Publication bias}

A statistical analysis of the Egger test and funnel plots were performed in all 23 studies. No significant publication bias was observed (Egger test, $P=0.624$;
Figure 5). Egger tests were also done in the subgroups, which also indicated no publication bias.

\section{DISCUSSION}

To evaluate the effect of isoflavone supplement on endometrial thickness we performed this meta-analysis with 23 randomized controlled trials of oral isoflavone supplement intervention (totally 2167 subjects received

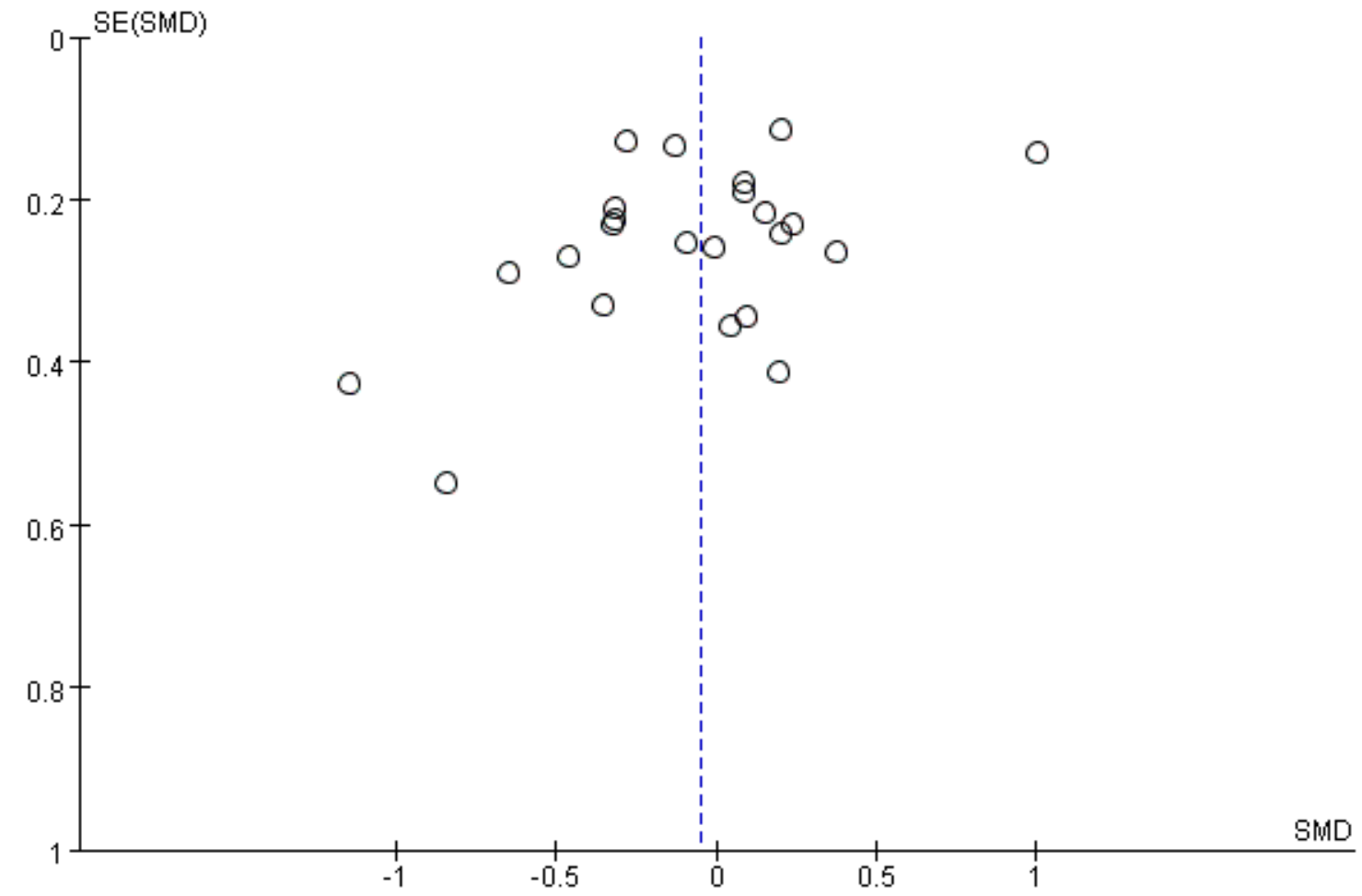

Figure 5: Funnel plot (with pseudo 95\% CIs) of all individual studies in the meta-analysis. Studies that evaluated the effect of oral isoflavone supplementation on endometrial thickness change were plotted with standard mean differences (SMDs) on the vertical axis and the SEs of the SMDs along the horizontal axis. Graph symbols were sized by weights 
isoflavone supplement or placebo). We found that isoflavone supplementation of more than $54 \mathrm{mg}$ per day could decrease endometrial thickness of $0.26 \mathrm{~mm}$ in postmenopausal women. The subjects from North America had a significant decrease $(-0.23 \mathrm{~mm})$ in endometrial thickness after isoflavone intervention, which was opposite to the response of Asian subjects $(0.23 \mathrm{~mm}$ increase). And no publication bias was observed.

Loss of estrogen could result in the increase of endometrial thickness [33]. Increase of endometrial thickness, especially in post-menopausal women, is an early pathologic feature and a predictor of endometrial cancer [34]. Dietary intake of phytoestrogens has been reported to protect women from estrogen-related diseases $[35,38]$. Isoflavone mainly from soy beans, has shown a protective effect on endometrial cells and breast cells in animal studies [36]. Isoflavone has also shown a modification effect on gene promoter methylation [37]. Hypermethylation in gene promoter regions was linked to many diseases like cancer [39] and metabolism syndrome [40]. Genistein as a subclass of isoflavone was considered to be the most active compounds and has been reported to affect DNA methylation [41, 42].

The effect of isoflavone on endometrial cancer in women has also been investigated by many observational studies [43-46]. Zhang et al. performed a meta-analysis about soy intake and endometrial cancer risk and found that soy food intake was associated with lower endometrial cancer risk in 10 related observational studies [46]. They found the highest reported soy intake compared with the lowest reduced the risk of endometrial cancer by $19 \%$. This finding shows that the intake of soy foods has an positive effect on human endometrial. Our results were in concordance with Zhang's results since endometrial thickening is a risk factor of endometrial cancer.

Our analysis suggested that isoflavone supplementation dose of more than $54 \mathrm{mg}$ per day might decrease endometrial thickness in post-menopausal women which were consistent with a cohort study. Ollberding et al. performed a prospective study followed up for an average of 13.6 years and observed an inverse association between dietary isoflavones intake and the risk of endometrial cancer [45]. Every 100g soybeans contains about $109 \mathrm{mg}$ isoflavone, this means if we want to gain more than $54 \mathrm{mg}$ isoflavone we need to consume more than $50 \mathrm{~g}$ soybeans or soy production. Dietary soy isoflavone intake in older Japanese American women was reported as $10.2 \mathrm{mg}$ per day [47]. More soy or soy product was needed to produce a beneficial effect on endometrial thickness in post-menupausal women.

Our results also show that subjects from North America had a significant decrease in endometrial thickness after isoflavone intervention, which was opposite to the response of Asian subjects. This difference could be contributed by different genetic background and dietary patterns between populations. Asian diet is rich in isoflavone due to more soy and soy products intake [48], which might result to a higher background level of isoflavone in their body; and additional supplementation may not be beneficial. North American had less isoflavone intake from their regular diet and the supplementation might be more effective [49].

This meta-analysis has some advantages: due to the nature of the studies, randomized double-blind controlled trials provided the most solid evidence for the effect of isoflavone supplementation on endometrial thickeness. In addition, with 23 RTCs and over 2100 subjects, the results from this large study should be stable with large power. Furthermore, the endometrial thickness from all the included studies was measured by transvaginal ultrasounds. The method is the most precise method in the current age, which minimized the heterogeneity of measurement [50]. Some potential limitations should be addressed. First, though we used the change of endometrial thickness before and after supplementation, the technology of endometrial thickness measurement improvement through years might affect the results. Second, the endometrial thickness may be affected by internal hormone exposure. Though 21 over 23 studies included only menopause women for the study, the different time duration after menopause might affect the endometrial thickness and response to hormone, which increase the heterogeneity of the study. The equol producer phenotype is important as it can reflect gut metabolite of soy isoflavone in vivo [51]. In human, only $30 \%-50 \%$ of the population are capable of converting daidzein to equol and equol's biological activities differs from its parent compound [52, 53]. However, we could not get the information about equol producers in almost all the included studies. In addition, the sample size is still not large enough, which limited the power to explore modification effect.

In summary, with meta-analysis we found that isoflavone supplementation might produce different effects on populations and the daily dose of isoflavone supplementation maybe important to the results. Additional large and long follow-up studies should be performed to confirm our results and explore the exact mechanism of isoflavone's effect on endometriun.

\section{MATERIALS AND METHODS}

\section{Search strategy and selection criteria}

We conducted a systematic meta-analysis according to the QUORUM (Quality of Reporting of Meta-analyses) guidelines [54]. An electronic search was performed on the PubMed (http://www.ncbi.nlm. nih.gov/pubmed) (from 1950 up to August 2015), Embase (http://www. embase.com) (from 1966 up to August 2015), the 
Cochrane Library database (http://www.cochrane. org), web of science (http://www.webofknowledge. com), CINAHL (http://www.ebscohost.com), and WHO ICTRP (http://www.who.int/trialsearch) up to August 2015. Additional search was conducted according to reviews and reference lists of relevant articles. The relevant text word "isoflavone" paired with "endometrial" or "endometrium" was used for searching. The inclusion criteria were as following:

(i) Completed, published, randomized, and placebocontrolled trials

(ii) With oral isoflavone, extractions of soy, or red clover as supplementation

(iii) Participants must have been treated with isoflavone for over 3 months to avoid the acute effect of isoflavone on endometrial thickness

(iv) Included participants were women of perimenopausal or postmenopausal with endometrial thickness measurement

The exclusion criteria were as following:

(i) Animal studies or in vitro studies.

(ii) The language of the article is not English.

(iii) Reviews, case-report, or comments.

Potentially relevant studies were collected in full text for further assessment of inclusion. All the papers were assessed for their relevance by two independent reviewers. And all the differences in data extraction were judged through discussion.

\section{Data extraction and quality assessment}

Mean change and variance of endometrial thickness were collected at the latest time point. Data on participants' characteristics (menopausal status, mean age, country, BMI), type of intervention (isoflavone source, type of supplementation, dose), duration of intervention, methods used to measure endometrial thickness, and sideeffect were also extracted from full articles. In the current study we got all the endometrial thickness data through the transvaginal ultrasounds detection. When the same intervention was published differently, data for analysis were extracted from the newest follow-up of the trails with longer duration of intervention. Authors were contacted for detail information like baseline endometrial thickness and the exact number of subjects who got endometrial thickness measurement etc.

The quality of the studies was assessed according to: concealment of treatment allocation, mention of randomization methods, appropriateness of randomization, mention of blinding methods, appropriateness of blinding, and whether the fate of all patients in the trial was known. A trial was scored one point for each area addressed, with a possible score ranging from 0 to 5 (highest level of quality) [55-57]

\section{Statistical analysis}

All analysis were conducted with Stata software (version 12.0; Stata Corporation, College Station, TX) and REVMAN software (version 5.0; Cochrane Collaboration, Oxford, United Kingdom). The primary outcome was defined as the change in endometrial thickness between baseline and end of the trial. If the change of endometrial thickness was not reported in the study, we calculated it using the methods recommended in the Cochrane Handbook (http://handbook.cochrane. org/) for Systemic Review and Follman D's theory[58] for overview of clinical trials with continuous variables by assuming equal variance among trials [10-32].

Summary estimates of standard mean differences (SMDs) and 95\% confidence intervals (95\% CIs) were obtained from random-effect models [58]. Heterogeneity of treatment effects between studies was assessed using Cochran's test with $P<0.1$ considered as statistical significant. The $\mathrm{I}^{2}$ statistic $>50 \%$ was considered heterogeneity significant between the trials [59]. We also conducted stratified analyses by the following factors to identify the sources of heterogeneity:

(i) age ( $=<60$ y or $>60 y)$

(ii) $\operatorname{BMI}\left(=<25 \mathrm{~kg} / \mathrm{m}^{2}\right.$ or $\left.>25 \mathrm{~kg} / \mathrm{m}^{2}\right)$

(iii) geographic region of subjects (north America, south America, Asia, Europe, Australia)

(iv) daily isoflavone dose (in aglycone equivalents, $=<54 \mathrm{mg} /$ day, $>54 \mathrm{mg} /$ day) and total supplementation isoflavone dose ( the total amount of isoflavone intake of the whole supplementation period, in aglycone equivalents, $=<14000 \mathrm{mg},>14000 \mathrm{mg}$ )

Potential publication bias was assessed with the Egger's test and represented graphically by Funnel plots [60].

\section{ACKNOWLEDGMENTS}

The authors' responsibilities were as follows: Ying Gao and Jie Liu conceived the idea and designed the study strategy; Jie Liu and Feixiang Yuan and Jian Gao: summarized the data and conducted the data analysis and all authors contributed to the data analysis and writing and revision of the manuscript.

\section{CONFLICTS OF INTEREST}

The authors declare no conflict of interest.

\section{FINANCIAL SUPPORT}

This research was supported by the 100 talented plan of Chinese Academy of Sciences (Ying Gao). The funders had no role in study design, data collection and analysis, decision to publish, or preparation of the manuscript. 


\section{REFERENCES}

1. Felix AS, Weissfeld JL, Pfeiffer RM, Modugno F, Black A, Hill LM, Martin J, Sit AS, Sherman ME and Brinton LA. Endometrial thickness and risk of breast and endometrial carcinomas in the prostate, lung, colorectal and ovarian cancer screening trial. International journal of cancer. 2014; 134:954-960.

2. Dueholm M, Moller C, Rydbjerg S, Hansen ES and Ortoft G. An ultrasound algorithm for identification of endometrial cancer. Ultrasound in obstetrics \& gynecology. 2014; 43:557-568.

3. Knight DC and Eden JA. A review of the clinical effects of phytoestrogens. Obstetrics and gynecology. 1996; 87:897904.

4. Eden JA. Phytoestrogens for menopausal symptoms: a review. Maturitas. 2012; 72:157-159.

5. Kuiper GG, Lemmen JG, Carlsson B, Corton JC, Safe SH, van der Saag PT, van der Burg B and Gustafsson JA. Interaction of estrogenic chemicals and phytoestrogens with estrogen receptor beta. Endocrinology. 1998; 139:42524263.

6. Messina M. Resolving the soy-breast cancer controversy. Journal of the American Dietetic Association. 2006; 106:363-364.

7. Hooper L, Madhavan G, Tice JA, Leinster SJ and Cassidy A. Effects of isoflavones on breast density in pre- and postmenopausal women: a systematic review and meta-analysis of randomized controlled trials. Human reproduction update. $2010 ; 16: 745-760$.

8. Thomas AJ, Ismail R, Taylor-Swanson L, Cray L, Schnall JG, Mitchell ES and Woods NF. Effects of isoflavones and amino acid therapies for hot flashes and co-occurring symptoms during the menopausal transition and early postmenopause: a systematic review. Maturitas. 2014; 78:263-276.

9. Ghazanfarpour M, Latifnejad Roudsari R, Treglia G and Sadeghi R. Topical administration of isoflavones for treatment of vaginal symptoms in postmenopausal women: A systematic review of randomised controlled trials. Journal of obstetrics and gynaecology. 2015; 35:783-787.

10. Alekel DL, Genschel U, Koehler KJ, Hofmann H, Van Loan MD, Beer BS, Hanson LN, Peterson CT and Kurzer MS. Soy Isoflavones for Reducing Bone Loss Study: effects of a 3-year trial on hormones, adverse events, and endometrial thickness in postmenopausal women. Menopause. 2015; 22:185-197.

11. Colacurci N, De Franciscis P, Atlante M, Mancino P, Monti M, Volpini G and Benvenuti C. Endometrial, breast and liver safety of soy isoflavones plus Lactobacillus sporogenes in post-menopausal women. Gynecological endocrinology. 2013; 29:209-212.

12. Quaas AM, Kono N, Mack WJ, Hodis HN, Felix JC, Paulson RJ and Shoupe D. Effect of isoflavone soy protein supplementation on endometrial thickness, hyperplasia, and endometrial cancer risk in postmenopausal women: a randomized controlled trial. Menopause. 2013; 20:840-844.

13. Oyama A, Ueno T, Uchiyama S, Aihara T, Miyake A, Kondo S and Matsunaga K. The effects of natural S-equol supplementation on skin aging in postmenopausal women: a pilot randomized placebo-controlled trial. Menopause. 2012; 19:202-210.

14. Steinberg FM, Murray MJ, Lewis RD, Cramer MA, Amato P, Young RL, Barnes S, Konzelmann KL, Fischer JG, Ellis KJ, Shypailo RJ, Fraley JK, Smith EOB and Wong WW. Clinical outcomes of a 2-y soy isoflavone supplementation in menopausal women. American journal of clinical nutrition. 2011; 93:356-367.

15. Evans M, Elliott JG, Sharma P, Berman R and Guthrie N. The effect of synthetic genistein on menopause symptom management in healthy postmenopausal women: a multicenter, randomized, placebo-controlled study. Maturitas. 2011; 68:189-196.

16. Kenny AM, Mangano KM, Abourizk RH, Bruno RS, Anamani DE, Kleppinger A, Walsh SJ, Prestwood KM and Kerstetter JE. Soy proteins and isoflavones affect bone mineral density in older women: a randomized controlled trial. The American journal of clinical nutrition. 2009; 90:234-242.

17. Anna RD, Cannata ML, Marini H, Atteritano M, Cancellieri F, Corrado F, Triolo O, Rizzo P, Russo S, Gaudio A, Frisina N, Bitto A, Polito F, et al. Effects of the phytoestrogen genistein on hot flushes, endometrium, and vaginal epithelium in postmenopausal women: A 2-year randomized, double-blind, placebo-controlled study. Menopause. 2009; 16:301-306.

18. Powles TJ, Howell A, Evans DG, McCloskey EV, Ashley S, Greenhalgh R, Affen J, Flook LA and Tidy A. Red clover isoflavones are safe and well tolerated in women with a family history of breast cancer. Menopause international. 2008; 14:6-12.

19. Manonai J, Chittacharoen A, Udomsubpayakul U, Theppisai $\mathrm{H}$ and Theppisai U. Effects and safety of Pueraria mirifica on lipid profiles and biochemical markers of bone turnover rates in healthy postmenopausal women. Menopause. 2008; $15: 530-535$

20. Zhang G, Qin L and Shi Y. Epimedium-derived phytoestrogen flavonoids exert beneficial effect on preventing bone loss in late postmenopausal women: a 24-month randomized, double-blind and placebo-controlled trial. Journal of bone and mineral research. 2007; 22:10721079.

21. Nahas EA, Nahas-Neto J, Orsatti FL, Carvalho EP, Oliveira ML and Dias R. Efficacy and safety of a soy isoflavone extract in postmenopausal women: a randomized, doubleblind, and placebo-controlled study. Maturitas. 2007; 58:249-258.

22. Marini H, Minutoli L, Polito F, Bitto A, Altavilla D, Atteritano M, Gaudio A, Mazzaferro S, Frisina A, Frisina 
N, Lubrano C, Bonaiuto M, D'Anna R, et al. Effects of the phytoestrogen genistein on bone metabolism in osteopenic postmenopausal women: A randomized trial. Annals of internal medicine. 2007; 146:839-847.

23. Cheng G, Wilczek B, Warner M, Gustafsson JA and Landgren BM. Isoflavone treatment for acute menopausal symptoms. Menopause. 2007; 14:468-473.

24. Imhof M, Gocan A, Reithmayr F, Lipovac M, Schimitzek $\mathrm{C}$, Chedraui $\mathrm{P}$ and Huber J. Effects of a red clover extract (MF11RCE) on endometrium and sex hormones in postmenopausal women. Maturitas. 2006; 55:76-81.

25. Nikander E, Rutanen E-M, Nieminen P, Wahlström T, Ylikorkala $\mathrm{O}$ and Tiitinen A. Lack of effect of isoflavonoids on the vagina and endometrium in postmenopausal women. Fertility \& Sterility. 2005; 83:137-142.

26. Crisafulli A, Marini H, Bitto A, Altavilla D, Squadrito G, Romeo A, Adamo EB, Marini R, D'Anna R, Corrado F, Bartolone S, Frisina N, Squadrito F. Effects of genistein on hot flushes in early postmenopausal women: A randomized, double-blind EPT- and placebo-controlled study. Menopause. 2004; 11:400-404.

27. Sammartino A, Di Carlo C, Mandato VD, Bifulco G, Di Stefano M, Nappi C. Effects of genistein on the endometrium: Ultrasonographic evaluation. Gynecological endocrinology. 2003; 17:45-49.

28. Penotti M, Fabio E, Modena AB, Rinaldi M, Omodei U, Vigano P. Effect of soy-derived isoflavones on hot flushes, endometrial thickness, and the pulsatility index of the uterine and cerebral arteries. Fertility and sterility. 2003; 79:1112-1117.

29. Murray MJ, Meyer WR, Lessey BA, Oi RH, DeWire RE and Fritz MA. Soy protein isolate with isoflavones does not prevent estradiol-induced endometrial hyperplasia in postmenopausal women: a pilot trial. Menopause. 2003; 10:456-464.

30. Han KK, Soares JM, Jr., Haidar MA, de Lima GR and Baracat EC. Benefits of soy isoflavone therapeutic regimen on menopausal symptoms. Obstetrics and gynecology. 2002; 99:389-394.

31. Hale GE, Hughes CL, Robboy SJ, Agarwal SK, Bievre M. A double-blind randomized study on the effects of red clover isoflavones on the endometrium. Menopause. 2001; 8:338-346.

32. Upmalis DH, Lobo R, Bradley L, Warren M, Cone FL, Lamia CA. Vasomotor symptom relief by soy isoflavone extract tablets in postmenopausal women: A multicenter, double-blind, randomized, placebo- controlled study. Menopause. 2000; 7:236-242.

33. MacGregor JI and Jordan VC. Basic guide to the mechanisms of antiestrogen action. Pharmacological reviews. 1998; 50:151-196.

34. Timmermans A, Opmeer BC, Khan KS, Bachmann LM, Epstein E, Clark TJ, Gupta JK, Bakour SH, van den Bosch T, van Doorn HC, Cameron ST, Giusa MG, Dessole S,
Dijkhuizen FP, Ter Riet G and Mol BW. Endometrial thickness measurement for detecting endometrial cancer in women with postmenopausal bleeding: a systematic review and meta-analysis. Obstetrics and gynecology. 2010; 116:160-167.

35. Soni M, Rahardjo TB, Soekardi R, Sulistyowati Y, Lestariningsih, Yesufu-Udechuku A, Irsan A and Hogervorst E. Phytoestrogens and cognitive function: a review. Maturitas. 2014; 77:209-220.

36. Gaete L, Tchernitchin AN, Bustamante R, Villena J, Lemus I, Gidekel M, Cabrera G and Astorga P. Daidzein-estrogen interaction in the rat uterus and its effect on human breast cancer cell growth. Journal of medicinal food. 2012; 15:1081-1090.

37. Sato N, Yamakawa N, Masuda M, Sudo K, Hatada I and Muramatsu M. Genome-wide DNA methylation analysis reveals phytoestrogen modification of promoter methylation patterns during embryonic stem cell differentiation. PloS one. 2011; 6:e19278.

38. Goodman MT, Wilkens LR, Hankin JH, Lyu LC, Wu AH and Kolonel LN. Association of soy and fiber consumption with the risk of endometrial cancer. American journal of epidemiology. 1997; 146:294-306.

39. Tao MH and Freudenheim JL. DNA methylation in endometrial cancer. Epigenetics. 2014; 5:491-498.

40. Jungbauer A and Medjakovic S. Phytoestrogens and the metabolic syndrome. The Journal of steroid biochemistry and molecular biology. 2014; 139:277-289.

41. Karsli-Ceppioglu S, Ngollo M, Adjakly M, Dagdemir A, Judes G, Lebert A, Boiteux JP, Penault LF, Bignon YJ, Guy L and Bernard-Gallon D. Genome-wide DNA methylation modified by soy phytoestrogens: role for epigenetic therapeutics in prostate cancer? Omics. 2015; 19:209-219.

42. Xie Q, Bai Q, Zou LY, Zhang QY, Zhou Y, Chang H, Yi L, Zhu JD and Mi MT. Genistein inhibits DNA methylation and increases expression of tumor suppressor genes in human breast cancer cells. Genes, chromosomes \& cancer. 2014; 53:422-431.

43. Budhathoki S, Iwasaki M, Sawada N, Yamaji T, Shimazu $\mathrm{T}$, Sasazuki S, Inoue M and Tsugane S. Soy food and isoflavone intake and endometrial cancer risk: the Japan Public Health Center-based prospective study. BJOG. 2015; 122:304-311.

44. Neill AS, Ibiebele TI, Lahmann PH, Hughes MC, Nagle $\mathrm{CM}$ and Webb PM. Dietary phyto-oestrogens and the risk of ovarian and endometrial cancers: findings from two Australian case-control studies. The British journal of nutrition. 2014; 111:1430-1440.

45. Ollberding NJ, Lim U, Wilkens LR, Setiawan VW, Shvetsov YB, Henderson BE, Kolonel LN and Goodman MT. Legume, soy, tofu, and isoflavone intake and endometrial cancer risk in postmenopausal women in the multiethnic cohort study. Journal of the National Cancer Institute. 2012; 104:67-76. 
46. Zhang GQ, Chen JL, Liu Q, Zhang Y, Zeng H and Zhao Y. Soy Intake Is Associated With Lower Endometrial Cancer Risk: A Systematic Review and Meta-Analysis of Observational Studies. Medicine. 2015; 94:e2281.

47. Rice MM, LaCroix AZ, Lampe JW, van Belle G, Kestin M, Sumitani M, Graves AB and Larson EB. Dietary soy isoflavone intake in older Japanese American women. Public health nutrition. 2001; 4:943-952.

48. Yamasaki K, Kayaba K and Ishikawa S. Soy and Soy Products Intake, All-Cause Mortality, and Cause-Specific Mortality in Japan: The Jichi Medical School Cohort Study. Asia-Pacific journal of public health. 2015; 27:531-541.

49. Douglas SM, Lasley TR and Leidy HJ. Consuming Beef vs. Soy Protein Has Little Effect on Appetite, Satiety, and Food Intake in Healthy Adults. The Journal of nutrition. 2015; 145:1010-1016.

50. Saha TK, Amer SA, Biss J, Thakare H, Williams S, Farrell $\mathrm{CT}$ and Calvert J. The validity of transvaginal ultrasound measurement of endometrial thickness: a comparison of ultrasound measurement with direct anatomical measurement. BJOG. 2004; 111:1419-1424.

51. Hoey L, Rowland IR, Lloyd AS, Clarke DB and Wiseman $\mathrm{H}$. Influence of soya-based infant formula consumption on isoflavone and gut microflora metabolite concentrations in urine and on faecal microflora composition and metabolic activity in infants and children. The British journal of nutrition. 2004; 91:607-616.

52. Landete JM, Arques J, Medina M, Gaya P, De La Rivas B and Munoz R. Bioactivation of Phytoestrogens: Intestinal Bacteria and Health. Critical reviews in food science and nutrition. 2015. doi:10.1080/10408398.2013.789823.
53. Lampe JW. Is equol the key to the efficacy of soy foods? The American journal of clinical nutrition. 2009; 89:1664S-1667S.

54. Moher D, Cook DJ, Eastwood S, Olkin I, Rennie D and Stroup DF. Improving the quality of reports of metaanalyses of randomised controlled trials: the QUOROM statement. Quality of Reporting of Meta-analyses. Lancet. 1999; 354:1896-1900.

55. Clark HD, Wells GA, Huet C, McAlister FA, Salmi LR, Fergusson D and Laupacis A. Assessing the quality of randomized trials: reliability of the Jadad scale. Controlled clinical trials. 1999; 20:448-452.

56. Moher D. How science takes stock: the story of metaanalysis. BMJ. 1998; 317:1088B.

57. Jadad AR, Moore RA, Carroll D, Jenkinson C, Reynolds DJ, Gavaghan DJ and McQuay HJ. Assessing the quality of reports of randomized clinical trials: is blinding necessary? Controlled clinical trials. 1996; 17:1-12.

58. Follmann D, Elliott P, Suh I and Cutler J. Variance imputation for overviews of clinical trials with continuous response. Journal of clinical epidemiology. 1992; 45:769773.

59. Higgins JP, Thompson SG, Deeks JJ and Altman DG. Measuring inconsistency in meta-analyses. BMJ. 2003; 327:557-560.

60. Egger M and Smith GD. Meta-Analysis. Potentials and promise. BMJ. 1997; 315:1371-1374. 